DOCTRINA

\title{
La transparencia como mecanismo de tutela de la privacidad de los consumidores y usuarios en contratos electrónicos
}

\author{
Transparency as a mechanism for protecting the privacy of consumers \\ and users in electronic contracts
}

\author{
Ínigo de la Maza Gazmuri \\ Universidad Diego Portales, Chile \\ Rodrigo Momberg Uribe \\ Pontificia Universidad Católica de Valparaíso, Chile
}

RESUMEN Las políticas de privacidad son extremadamente frecuentes en los sitios web. Sin embargo, ¿ resultan suficientes para entender que el titular de los datos ha entregado su autorización para el tratamiento? Nuestra opinión es que no. El requisito al que queremos prestar atención es la transparencia. En otras palabras, defendemos que si dichas políticas no son transparentes, en el sentido en que resultan accesibles y su texto es comprensible, no es posible afirmar que el titular de los datos ha autorizado su tratamiento.

PALABRAS CLAVE Privacidad, contrato, consumidores, transparencia.

ABSTRACT Privacy policies are highly recurrent on websites. Are they, however, enough to demonstrate that the data subject has authorized their processing? Our opinion is that they are not. The condition we want to analyse is transparency. In other words, we claim that if those policies are not transparent, in the sense that if they are not easily accessible nor their text is clear and legible, it is not possible to conclude that the data subject has authorized the processing of personal data.

KEYWORDS Privacy, contract, consumers, transparency. 


\section{Introducción}

Según reportan Solove y Hartzog (2014: 594) para el ámbito estadounidense, si bien en 1998 únicamente el $2 \%$ de los sitios web disponían de políticas de privacidad, al 2001 casi todos los sitios comerciales populares disponían de una. Probablemente -aunque no hemos hechos un estudio empírico-, al 2018 pueda decirse algo semejante en Chile.

En un trabajo anterior (De la Maza y Momberg, 2017) sostuvimos que no todos aquellos documentos que contienen políticas de privacidad que se entienden aceptadas por los consumidores y usuarios ${ }^{1}$ de un sitio pueden considerarse como contratos, pues falta aceptación de sus términos. En ese escenario, salvo que se trate de alguna de las excepciones legales en las que no se requiere autorización del titular para tratar sus datos, resulta evidente que el tratamiento de datos es completamente ilícito. ¿Cómo podría entenderse que aceptó el tratamiento si no se aceptaron los términos del contrato que contenían las políticas de privacidad?²

En este trabajo nos interesa considerar otro escenario. Uno en el que puede afirmarse que existe contrato, pues, formalmente al menos, sus términos han sido aceptados por el consumidor o usuario. En ese escenario nuestra pregunta es si puede entenderse que, por el hecho de haber aceptado el contrato, se puede a la vez asumir que el titular de los datos ha autorizado su tratamiento en el sentido en que lo exige el artículo 4 de la Ley 19.628.

Creemos que no. No sin más, al menos. No basta con que el consumidor o usuario haya podido conocer la existencia de los términos y condiciones para que se entienda que aceptó el tratamiento de sus datos en los términos en que lo establece su política de privacidad.

Acaso la razón más evidente para afirmar que el solo conocimiento y aceptación formal de los términos y condiciones no basta, al menos en situaciones que caigan dentro del ámbito de aplicación de la Ley 19.496, sea que las políticas de privacidad contengan cláusulas abusivas. Así lo ha fallado, al menos, una vez la Corte Suprema. ${ }^{3}$ El hecho de que un consumidor acepte una cláusula abusiva no la convierte en lícita; en este sentido, entonces, el consentimiento es jurídicamente irrelevante.

Nuestra atención, sin embargo, se dirige aquí a un ángulo distinto. No nos interesa lo que podríamos denominar el aspecto sustantivo de la abusividad, el desequilibrio

1. Empleamos las expresiones «consumidores» $\mathrm{y}$ «usuarios» a lo largo de este trabajo porque no necesariamente quienes utilizan un sitio web tienen calidad de consumidores en el sentido que asigna la Ley 19.496 a esta expresión. Sobre el tema, véase Momberg (2013: 3-16).

2. Empleamos la expresión "políticas de privacidad» para referirnos a las cláusulas que disciplinan diversos aspectos de la vida privada de los consumidores y usuarios, aunque generalmente se limiten al tratamiento de sus datos personales.

3. Corte Suprema de Chile, rol 1533-2015. 
importante en perjuicio del consumidor. Nos interesa, en cambio, lo que vamos a denominar el «requisito de transparencia», es decir, la posibilidad de acceso y la comprensibilidad de las cláusulas que configuran las políticas de privacidad.

La conclusión que defendemos en este trabajo es que si no se satisface el requisito de transparencia respecto de las políticas de privacidad, no puede estimarse que el titular de los datos ha autorizado su tratamiento.

El camino que seguimos para llegar a esta conclusión es el siguiente. Comenzamos mostrando dos casos que ilustran el problema que nos interesa, en los cuales no se discute la existencia del contrato, pero sí el hecho de que la política de privacidad resultara oponible al titular de los datos, precisamente por problemas de transparencia de esa política. A continuación, procuramos mostrar la situación del requisito de transparencia en el ámbito europeo y, en términos más particulares - es decir, referidos a contratos electrónicos y políticas de privacidad-, en el ámbito estadounidense. A partir de ellos, detectamos dos dimensiones del requisito de transparencia y las examinamos en el ámbito nacional. En tercer lugar, consideramos la situación de algunos contratos electrónicos en Chile que contienen políticas de privacidad y mostramos ejemplos de infracciones al requisito de transparencia.

\section{Dos casos y tres problemas relativos a las políticas de privacidad}

\section{La FTC y Sears}

En septiembre de 2009, la Federal Trade Commission (FTC) accionó en contra de Sears Holding Management Corp. ${ }^{4}$ señalando que la compañía había violado la sección 5 de la FTC Act. Señaló que un programa de software ofrecido en línea por Sears le permitía a la empresa rastrear la conducta en línea de los consumidores. Una vez instalado en el computador de los consumidores, el programa transmitía información a Sears respecto de todos los sitios que visitaban los consumidores.

El uso del software estaba disciplinado por una licencia y antes de descargarlo se requería que el consumidor o usuario indicara que había leído el documento que contenía la política de privacidad. La FTC no cuestionó el carácter contractual del documento. En cambio, consideró que había existido una práctica injusta o engañosa (unfair or deceptive) por parte de Sears.

La práctica injusta o engañosa que reprochó la FTC a Sears no consistía, exactamente, en que no hubiera informado a los consumidores la función de rastreo del software. De hecho, ésta se detallaba en el contrato. El problema, más bien, tenía que ver con la manera en que se informaba esa función.

4. Caso Sears Holdings Mgmt. Corp., docket C-4264. Seguimos aquí la descripción de Gindin (2009: 1-4). Sobre el tema puede consultarse también Fang (2010). 
Para entender esto, resulta útil advertir que este software se instalaba cuando el consumidor o usuario procuraba acceder a una aplicación referida a una comunidad en línea que suministraba información acerca de los productos, servicios y ofertas de Sears y que ésta le ofrecía. La información que recibían los consumidores en un principio era sobre la aplicación, no las funciones del programa de rastreo. Los consumidores únicamente podían acceder a información sobre el programa una vez que se encontraban bastante avanzados en el proceso de registro para obtener la aplicación, en el momento en que se les requería aceptar los términos de la licencia relativa a la privacidad de los consumidores. Pero aun al llegar al documento que contenía las políticas de privacidad, la información sobre las funciones del programa de rastreo aparecía recién en la línea 75 del documento.

Entre sus alegaciones - y en lo que interesa a este trabajo-, la FTC señaló lo siguiente:

El requerido ha faltado en informar adecuadamente que la aplicación de software, una vez instalada, podría: monitorear casi toda la actividad relacionada con internet que se realice en los computadores de los consumidores, incluyendo la información intercambiada entre los consumidores y sitios web distintos a aquéllos de propiedad, operados o afiliados al requerido, información entregada en sesiones seguras al interactuar con sitios web de terceros, carros de compra, y cuentas en línea, así como headers de correo electrónico operado vía web; rastrear ciertas actividades no relacionadas con internet que se efectúen en tales computadores; $y$ transmitir casi toda la información monitoreada (excluyendo categorías seleccionadas o información filtrada) a los servidores del requerido. Estos hechos debieron ser esenciales para los consumidores al decidir si instalar el software. La falta del requerido de informar estos hechos, a la luz de las declaraciones efectuadas, fue, y es, una práctica engañosa. [...] Los actos y prácticas del requerido, como se han descrito en este procedimiento, constituyen actos o prácticas abusivas o engañosas que afectan al comercio, transgrediendo la sección 5(a) de la Federal Trade Commission Act.

El pasaje indica que, como ya ha quedado dicho, el reproche consiste en que no se informó adecuadamente a los consumidores sobre las funciones de rastreo del programa. La situación resulta extremadamente importante, pues se estima que esa información resultaba determinante (material) para la decisión de los consumidores de instalar el programa. La FTC estimó que esta falla en la forma de suministrar la información configura una práctica engañosa para el derecho estadounidense.

\section{El Tribunal Supremo y la cláusula suelo}

La sentencia del 9 de mayo de 2013 del Tribunal Supremo español resolvió una acción a través de la cual varias asociaciones de consumidores habían demandado a diversas entidades bancarias por incluir en sus contratos de mutuo hipotecario de «cláusulas 
suelo», es decir, cláusulas que fijaban límites mínimos a las variaciones del tipo de interés. ${ }^{5}$

Por supuesto, la tentación inicial consiste en afirmar que dichas cláusulas establecen un desequilibrio importante y, por lo mismo, quedan sujetas a control de contenido. Sin embargo, en el ámbito español ese control de contenido no es posible respecto de los elementos esenciales del contrato. Tratándose del contrato de mutuo, el interés - es decir, el precio que se paga por disponer del dinero- es ciertamente un elemento esencial.

La sentencia consideró, entonces, que no se trataba de un problema del contenido de las cláusulas suelo, sino de su transparencia. En palabras de Pertiñez Vílchez (2013: 5):

El criterio empleado para considerar abusivas las cláusulas suelo por una falta de transparencia es realmente sencillo y se puede sintetizar de la siguiente manera: al no informar la entidad financiera suficientemente de la existencia de una cláusula suelo antes de la celebración del contrato y de sus consecuencias en caso de un escenario previsible de bajada del tipo de referencia, su inclusión en el contrato a hurtadillas, oculta entre una profusión de cláusulas financieras, provoca una alteración subrepticia del precio del crédito, sobre el cual el prestatario creía haber prestado su consentimiento a partir de la información proporcionada por la entidad en la fase precontractual. En la perspectiva del consumidor, dicho precio estaba constituido por el diferencial aplicable a un tipo de referencia variable (normalmente el Euríbor). La sentencia llega a hablar de oferta «engañosa».

Señala Pertiñez Vílchez (2013: 6) que este argumento tiene como mérito haber desvinculado la transparencia del control de incorporación y, por otra parte, estimar que una cláusula puede ser abusiva no solo cuando establece un desequilibrio importante, sino cuando altera la representación del consumidor acerca de los riesgos que involucra dicho contrato. ${ }^{6}$

\section{Tres problemas}

En nuestra opinión, los dos casos que hemos presentado tan sucintamente resultan interesantes porque nos permiten afinar nuestra comprensión de los problemas que pueden suscitar las cláusulas que en contratos electrónicos buscan regular distintas dimensiones de la privacidad de los usuarios.

Un primer problema, que hemos tratado en otro trabajo (De la Maza y Momberg, 2017) - y sobre el que volvemos en la última sección de éste-, es si el documento que

5. Ha estudiado con atención el tema Morales Moreno (2014). Véase también Cañizares Laso (2015) y Pertiñez Vílchez (2013).

6. En el mismo sentido, véase más adelante la referencia a la jurisprudencia de la CJUE. 
contiene la política de privacidad (compuesta por una o más cláusulas) tiene o no el carácter de un contrato. Si no lo tiene, entonces no puede asumirse que el titular de los datos aceptó el tratamiento que pretende hacer el sitio web (en el caso de la FTC, Sears) o bien que se aceptó la cláusula de suelo (en el caso del Tribunal Supremo).

Sin embargo - he aquí el segundo problema-, puede suceder que, como sucede en ambos casos, no se cuestione la existencia del contrato, sino que, a diferencia de los dos casos, se cuestione el carácter abusivo de la cláusula que se impugna. Así, por ejemplo, en una demanda de interés colectivo y difuso del Servicio Nacional del Consumidor (Sernac) de Chile en contra de Falabella el 24 de mayo de 2015,7 Sernac consideraba que la cláusula c) de los términos y condiciones mantenidos en el sitio web de Falabella en esa fecha, denominada «Protección de sus datos personales», resultaba abusiva. ${ }^{8}$ En su argumentación, Sernac mezcla argumentos propios de eventuales infracciones a la Ley 19.628 sobre Protección de la Vida Privada ${ }^{9}$ con otros propios de la Ley $19.496 .{ }^{10} \mathrm{~A}$ partir de estos últimos, considera que, en los hechos, la

7. Decimosegundo Juzgado Civil de Santiago, rol 6924-2015.

8. El contenido de la cláusula era el siguiente: «Los datos personales que entregue el usuario solo podrán ser utilizados por Falabella Retail para perfeccionar contratos, recibir pagos y mejorar la labor de información y comercialización de los productos y servicios con el usuario; y no podrán ser entregados a terceros no relacionados con Falabella Retail. Dicha entrega será revocable por el usuario. El usuario dispondrá siempre de los derechos de información, rectificación y cancelación de sus datos personales conforme a la Ley 19.628 sobre protección de datos de carácter personal. Para ejercer esos derechos, efectuar dicha revocación o modificar la información personal registrada en el sitio, el usuario deberá enviar un correo electrónico a servicios@falabella.cl o comunicarse al teléfono 6003805000 en horario hábil».

9. Los argumentos son los siguientes: en la especie, el proveedor establece un tratamiento amplio e indefinido de los datos personales que los consumidores han obligatoriamente entregado para registrarse en la página web de la demandada. Asimismo, a partir de los términos en que está redactada la cláusula, también se arroga la facultad de modificar el contrato, lo que se desprende de una de las finalidades que tendría la autorización que la demandada recoge a propósito de la cláusula en cuestión. En consecuencia, la cláusula en análisis no se circunscribe debidamente a la regulación de la Ley 19.628 sobre Protección de la Vida Privada, en particular, respecto al tratamiento de datos personales. En todo caso, debe entenderse que la protección que la Ley 19.628 brinda para el tratamiento de los datos personales alcanza solo a su titular y al proveedor. Por lo tanto, que pretenda el proveedor que la autorización que recaba para sí alcance también a terceros desconocidos para el consumidor, no es sino una muestra de la indefensión que la cláusula en cuestión estaría causando a los consumidores y, a su vez, demuestra el desequilibrio que también la misma presenta respecto del consumidor y el proveedor. Por otra parte, el proveedor no informa, veraz y oportunamente, sobre quiénes tendrían acceso a la información ni tampoco sobre qué tipo de tratamiento les darían a estos datos, por cuanto la cláusula solamente informa a quiénes no se les hará entrega de los datos personales de los consumidores registrados en la página web y qué uso le darán a dichos datos.

10. Los argumentos son los siguientes: el hecho de que se escriba que no se hará entrega de esta información a terceros no relacionados con Falabella no valida la legalidad de la cláusula, ya que para que el proveedor haga uso de los datos personales de los consumidores registrados, requiere la autorización 
política de privacidad del contrato, contra las exigencias de la buena fe, genera un desequilibrio importante entre los derechos y obligaciones de las partes en perjuicio de los consumidores.

Al prestar atención a los dos casos que hemos presentado, descubrimos que no cuestionan el contenido de las cláusulas. La FTC no reprocha a Sears que las facultades que se arroga sean demasiado amplias. El Tribunal Supremo, por su parte, señala que, si se hubiera informado suficientemente, la cláusula sería lícita. Lo que se critica en el caso de la FTC es que el acceso a la información respecto de las funciones de rastreo es inadecuado y que eso determina una práctica engañosa.

He aquí el tercer problema. Puede ser el caso que no se cuestione ni la existencia del contrato ni que sus cláusulas establezcan un desequilibrio importante para las partes; lo que en cambio se reprocha es que se informó inadecuadamente. O, como sugiere Gindin (2009: 3) respecto del caso de la FTC, que cierta información determinante - como la relativa a la privacidad de los consumidores- no se entregó de manera clara y conspicua 0 «transparente».

\section{El requisito de transparencia}

Según veremos, el requisito de transparencia no ha sido examinado detalladamente en el ámbito nacional. Por lo mismo, para presentarlo nos servimos primero de algunos desarrollos generales a nivel europeo y, luego, de otros más específicos sobre contratos electrónicos y políticas de privacidad en el ámbito estadounidense. Luego presentamos la situación chilena.

\section{Europa}

Según ha sugerido Micklitz (2014: 142), el requisito de transparencia del contenido de un contrato de adhesión corresponde al elemento formal de la inequidad (unfairness) de las cláusulas de un contrato por adhesión que establece la Directiva 93/13/CEE del 5 de abril de 1993, sobre las cláusulas abusivas en los contratos celebrados con consumidores. La formulación de este requisito se encuentra en el artículo 5 de dicha directiva, cuyo texto señala:

\footnotetext{
expresa y escrita de estos últimos. En este sentido, el establecimiento de una cláusula de tratamiento de datos personales de carácter amplio, indefinido e, incluso, con la posibilidad de entregarles a terceros dichos datos personales, genera un desequilibrio importante en los derechos y obligaciones de las partes, lo que la transforma en una cláusula contraria a las exigencias de la buena fe, según el artículo 16 inciso primero letra g) de la Ley de Protección al Consumidor. Del mismo modo, y al arrogarse a través de la cláusula en cuestión la facultad de "perfeccionar contratos», a propósito de la autorización no ajustada a derecho que recoge de los consumidores para el tratamiento de sus datos personales, la demandada se genera la prerrogativa de modificar unilateralmente el contrato.
} 
En los casos de contratos en que todas las cláusulas propuestas al consumidor o algunas de ellas consten por escrito, estas cláusulas deberán estar redactadas siempre de forma clara y comprensible. En caso de duda sobre el sentido de una cláusula, prevalecerá la interpretación más favorable para el consumidor. Esta norma de interpretación no será aplicable en el marco de los procedimientos que establece el apartado 2 del artículo 7 de la presente directiva.

Este requisito ha sido consagrado en diversos instrumentos legislativos de la Unión. Como es de presumir, el legislador europeo exige a los proveedores que comuniquen o pongan a disposición del usuario, previamente, los términos del contrato que se pretende celebrar. Así, además de la Directiva 93/13/CEE ya considerada, la Directiva 2011/83/UE sobre los derechos de los consumidores establece en su artículo 6.1 los requisitos de información que deben cumplir los contratos a distancia y aquéllos celebrados fuera de los establecimientos comerciales, disponiendo, entre otros, que el proveedor facilitará al consumidor, de manera clara y comprensible, antes de la celebración del contrato, información sobre las características de los bienes o servicios, la identidad del comerciante, el precio total de los bienes o servicios, la existencia del derecho de desistimiento, las garantías y la duración del contrato.

En el mismo sentido, el artículo 5 de la Directiva 2002/65/EC sobre comercialización a distancia de servicios financieros destinados a los consumidores, establece que «el proveedor comunicará al consumidor todas las condiciones contractuales, así como la información contemplada en el apartado 1 del artículo 3 y en el artículo 4, en soporte de papel u otro soporte duradero accesible al consumidor y puesto a su disposición con la suficiente antelación antes de que el consumidor asuma obligaciones mediante cualquier contrato a distancia u oferta». Por su parte, el artículo 22 de la Directiva 2006/123/EC, relativa a los servicios en el mercado interior, establece también la obligación para los prestadores de poner a disposición de los destinatarios, con la debida antelación a la celebración del contrato, información de fácil acceso sobre los principales términos del servicio. Finalmente, el artículo 10.3 de la Directiva 2000/31/ EC sobre comercio electrónico, dispone que «las condiciones generales de los contratos facilitadas al destinatario deben estar disponibles de tal manera que éste pueda almacenarlas y reproducirlas».

Sin embargo, la mera provisión de los términos del contrato por parte del proveedor no es suficiente. Si así fuese, no habría mayor diferencia entre los diversos deberes u obligaciones de información que tradicionalmente se establecen en materia de derecho del consumidor, y el principio o control de transparencia. La diferencia entre ambas instituciones radica en que el control de transparencia exige más que la sola entrega de información por parte del proveedor, ya que requiere además que tales términos se presenten de una manera clara, comprensible e inequívoca para el usuario medio. Ello determina que el control de transparencia vaya más allá de un 
mero examen formal, requiriendo evaluar si la entrega de información cumple con las condiciones de claridad, legibilidad y certidumbre.

Nuevamente, la legislación europea nos entrega las pautas al respecto. Así, el artículo 5 de la citada Directiva 93/13 sobre cláusulas abusivas establece que, «en los casos de contratos en que todas las cláusulas propuestas al consumidor o algunas de ellas consten por escrito, estas cláusulas deberán estar redactadas siempre de forma clara $y$ comprensible». La aplicación de la excepción al examen de abusividad de las cláusulas sobre el objeto principal del contrato y al precio del artículo 4.2 de la misma Directiva está también sujeta a que dichas cláusulas se hayan redactado de manera clara y comprensible. También, el artículo 10 de la Directiva 2000/31/EC sobre comercio electrónico exige que el prestador de servicios facilite de manera clara, comprensible e inequívoca, antes que el destinatario del servicio efectúe un pedido, información relevante sobre, por ejemplo $-\mathrm{y}$ de manera relevante para lo expuesto en este trabajo-, los diferentes pasos técnicos que deben darse para celebrar el contrato, añadiendo que las condiciones generales de los contratos deben estar disponibles de tal manera que el destinatario pueda almacenarlas y distribuirlas. Asimismo, el artículo 3.2 de la citada Directiva 2002/65/EC establece que

la información a que se refiere el apartado 1, cuyo fin comercial deberá indicarse inequívocamente, se comunicará de manera clara y comprensible por cualquier medio que se adapte a la técnica de comunicación a distancia utilizada, respetando debidamente, en particular, los principios de buena fe en las transacciones comerciales y los principios que regulan la protección de las personas que, con arreglo a la legislación de los Estados miembros, carecen de capacidad de obrar, como por ejemplo los menores de edad.

El artículo 22.4 de la referida Directiva 2006/123/EC sobre servicios establece que

los Estados miembros harán lo necesario para que la información contemplada en el presente capítulo que el prestador debe facilitar esté disponible o se proporcione de forma clara e inequívoca, con la debida antelación antes de la celebración del contrato o, cuando no haya contrato por escrito, antes de la prestación del servicio.

Por su parte, la Directiva 2011/83/UE sobre los derechos de los consumidores establece en su artículo 8.1 que «en los contratos a distancia, el comerciante facilitará al consumidor la información exigida en el artículo 6, apartado 1, o la pondrá a su disposición de forma acorde con las técnicas de comunicación a distancia utilizadas, en términos claros y comprensibles. Siempre que dicha información se facilite en un soporte duradero deberá ser legible». El artículo 6.7 de la misma Directiva dispone que «los Estados miembros podrán mantener o introducir, en su legislación nacional, requisitos de carácter lingüístico en relación con la información contractual a fin de garantizar que dicha información pueda ser comprendida fácilmente por los consumidores». 
Por último, debe destacarse que el reciente Reglamento 2016/79 del Parlamento Europeo y del Consejo sobre protección de las personas físicas en lo que respecta al tratamiento de datos personales, reconoce expresamente en sus considerandos el principio de transparencia. Así, el considerando trigésimo noveno expresa que «el principio de transparencia exige que toda información y comunicación relativa al tratamiento de dichos datos sea fácilmente accesible y fácil de entender, y que se utilice un lenguaje sencillo y claro", a lo que el considerando quincuagésimo octavo agrega que «el principio de transparencia exige que toda información dirigida al público o al interesado sea concisa, fácilmente accesible y fácil de entender, y que se utilice un lenguaje claro y sencillo, y, además, en su caso, se visualice». ${ }^{11}$

En lo que interesa a este trabajo, el principio de transparencia se concreta en particular en las normas sobre consentimiento y los derechos del interesado relativos al tratamiento de sus datos personales. $\mathrm{Al}$ respecto, el artículo 7.2 señala que

si el consentimiento del interesado se da en el contexto de una declaración escrita que también se refiera a otros asuntos, la solicitud de consentimiento se presentará de tal forma que se distinga claramente de los demás asuntos, de forma inteligible $y$ de fácil acceso y utilizando un lenguaje claro y sencillo. No será vinculante ninguna parte de la declaración que constituya infracción del presente Reglamento.

Por su parte, el artículo 12.1, bajo el título «Transparencia de la información, comunicación y modalidades de ejercicio de los derechos del interesado», prescribe:

El responsable del tratamiento tomará las medidas oportunas para facilitar al interesado toda información indicada en los artículos 13 y 14, así como cualquier comunicación con arreglo a los artículos 15 a 22 y 34 relativa al tratamiento, en forma concisa, transparente, inteligible y de fácil acceso, con un lenguaje claro y sencillo, en particular cualquier información dirigida específicamente a un niño. La información será facilitada por escrito o por otros medios, inclusive, si procede, por medios electrónicos. Cuando lo solicite el interesado, la información podrá facilitarse verbalmente siempre que se demuestre la identidad del interesado por otros medios.

Si revisamos la jurisprudencia de la Corte de Justicia de la Unión Europea (CJUE), se constata que ella se ha pronunciado en diversas ocasiones respecto al concepto y extensión del principio de transparencia. Así, en RWE con Verbraucherzentrale Nordrhein-Westfalen, ${ }^{12}$ la Corte señaló que el deber de transparencia a que están sujetos

11. Otros considerandos que mencionan el principio de transparencia son los números sexagésimo, septuagésimo primero y septuagésimo octavo. El Reglamento aplica este principio no solo a la información que debe ser provista al titular de los datos, sino también a las actuaciones de los agentes públicos y privados involucrados en el tratamiento de ellos (artículos 26,40 a 43 y 88).

12. Sentencia del caso RWE con Verbraucherzentrale Nordrhein-Westfalen, C-92/11, 26 de abril de 2013. 
los contratos de adhesión no se satisface por la mera referencia, en las condiciones generales o cláusulas tipo, a disposiciones legales o reglamentarias que puedan aplicarse al contrato, sino que es esencial que el consumidor sea informado del contenido de las disposiciones de que se trate, de manera de resguardar el interés legítimo del consumidor de conocer y prever las consecuencias de la aplicación de dichas disposiciones.

El considerando vigésimo y el artículo 5 de la Directiva 93/13 sobre cláusulas abusivas fue interpretado por la CJUE en el caso Hatóság con Invitel, en el sentido de que «el consumidor debe contar con la oportunidad real de tener conocimiento de todas las cláusulas que forman parte de las cláusulas generales y de sus consecuencias. Por otra parte, el artículo 5 de la Directiva establece la obligación de formular las cláusulas de manera clara y comprensible». ${ }^{13}$ La Corte agregó que "por consiguiente, para apreciar el carácter "abusivo" en el sentido del artículo 3 de la Directiva, tiene una importancia esencial que el consumidor pueda prever, basándose en criterios claros y comprensibles, las modificaciones de las condiciones generales que pueda realizar el profesional en lo referido a los gastos relacionados con el servicio que deba prestarse». ${ }^{14}$

En el mismo sentido, en Kásler con OTP Jelzálogbank, ${ }^{15}$ la Corte señaló que la exigencia de transparencia de las cláusulas contractuales establecida por la Directiva 93/13 no puede reducirse únicamente al carácter comprensible de éstas en un plano formal y gramatical, de manera que un consumidor medio esté no solo al tanto de la existencia de los términos del contrato, sino que sea capaz de evaluar las consecuencias económicas y jurídicas de su aplicación y cumplimiento.

Resulta, además, interesante destacar qué instrumentos de derecho contractual uniforme incluyen también disposiciones sobre transparencia en su normativa. Los Principios Europeos de Derecho de los Contratos (PECL) establecen en su artículo 2:104, relativo a los términos contractuales no negociados de manera individual, que

1) los términos de un contrato que no hayan sido objeto de negociación individual solo podrán oponerse contra una parte que no tuviera conocimiento de ellos cuando la parte que los invoca hubiera adoptado medidas razonables para hacerlos notar a la otra parte antes de la conclusión del contrato o en el momento de dicha conclusión.

2) La mera alusión referencial en el documento a los términos del contrato no es suficiente para considerar que se han hecho notar adecuadamente a la otra parte, aunque ésta haya firmado el documento.

13. Sentencia de Hatóság con Invitel, C-472/10, 26 de abril de 2012, párrafo 27.

14. Sentencia de Hatóság con Invitel, párrafo 28.

15. Sentencia de Kásler con OTP Jelzálogbank, C-26/13, 30 de abril de 2014. 
Los Comentarios Oficiales destacan que si los términos no negociados no se han hecho notar adecuadamente al destinatario, se debe entender que no se han incorporado al contrato celebrado entre las partes.

El Draft Common Frame of Reference (DCFR) contiene una norma similar en su artículo 2, 9:103, pero agrega una regla especial para los contratos celebrados por medios electrónicos en su párrafo segundo: «Si un contrato se concluyese por medios electrónicos, la parte que provea cualesquiera términos que no hayan sido negociados individualmente podrá invocarlos sólo si los hubiera puesto a disposición de la otra parte por escrito». Los Comentarios Oficiales subrayan que la norma refleja lo dispuesto en la Directiva 2000/31/EC sobre comercio electrónico, a la cual ya se ha hecho referencia. La expresión "por escrito» debe entenderse como cualquier texto que conste en un medio que permita su lectura, almacenamiento y reproducción posterior (artículo 1, 1:106).

Más directamente, el artículo 2, 9:402 del DCFR establece el deber de transparencia en los términos no negociados individualmente. La norma dispone:

1) La persona que provee términos que no han sido negociados individualmente tiene el deber de asegurarse que ellos han sido redactados y comunicados en lenguaje claro e inteligible.

2) En un contrato entre un comerciante y un consumidor, un término que ha sido provisto por el comerciante en incumplimiento del deber de transparencia impuesto en el párrafo 1 puede considerarse abusivo por ese solo motivo.

De acuerdo con los Comentarios Oficiales, la norma estaría basada en el artículo 5 de la Directiva 93/13/EEC sobre cláusulas abusivas. Como puede apreciarse, la disposición se centra en el segundo aspecto del principio de transparencia, esto es, ya no la mera entrega de información, sino su calidad. Aunque la norma no se limita a contratos celebrados con consumidores, la infracción al deber de transparencia en este tipo de contratos puede implicar que la cláusula respectiva sea considerada abusiva por ese solo hecho. La norma debe ser complementada con aquélla que dispone que la información precontractual debe ser provista de manera clara y precisa, y expresada en lenguaje simple e inteligible (artículo 2, 3:106).

Por último, la fallida propuesta de la Comisión Europea de una normativa común de compraventa europea (CESL) incluye en sus disposiciones normas basadas en los ya citados artículos de los PECL y del DCFR. Así, el artículo 70 establece el deber de llamar la atención sobre las cláusulas contractuales no negociadas individualmente, disponiendo:

1) Las cláusulas contractuales impuestas por una de las partes y no negociadas individualmente a tenor del artículo 7 podrán ser invocadas contra la otra parte sólo si ésta tuvo conocimiento de ellas, o si la parte que las impuso adoptó las medidas ra- 
zonables para que la otra parte tuviera conocimiento de ellas antes de la celebración del contrato o durante dicha celebración.

2) A efectos del presente artículo, en las relaciones entre un comerciante y un consumidor, la mera referencia en el texto del contrato no bastará para considerar que se han adoptado medidas suficientes para que el consumidor tenga conocimiento de las cláusulas contractuales, aun cuando el consumidor haya suscrito el documento.

El artículo 82 impone asimismo el deber de transparencia en las cláusulas contractuales no negociadas individualmente, al establecer que «cuando un comerciante incorpore cláusulas contractuales que no hayan sido negociadas individualmente con el consumidor a tenor del artículo 7 , tendrá el deber de asegurarse de que se redacten y comuniquen en un lenguaje sencillo y comprensible». ${ }^{16}$

En definitiva, parece claro que en el ámbito europeo el requisito de transparencia exige al proveedor otorgar a la otra parte la oportunidad para que, antes de la celebración del contrato, pueda conocer sus términos, lo que asegura además que tales términos sean comprensibles para un usuario medio (Loos, 2015: 179-180).

\section{El ámbito estadounidense}

Junto al derecho de la Unión Europea, nos parece conveniente considerar algún desarrollo en el ámbito estadounidense. Si bien resulta cierto que el derecho del consumo europeo tiene mucha más importancia para el ámbito nacional que el estadounidense, creemos que este último ofrece la ventaja de que ha considerado con mayor detalle las cuestiones relativas a los contratos electrónicos y, como veremos de inmediato, específicamente respecto de las políticas de privacidad.

Según señalan Solove y Hartzog (2014: 588), la FTC ha sido el componente más importante del sistema regulatorio de la privacidad en Estados Unidos. Aun cuando se trata de un órgano cuya función es proteger la libre competencia, el capítulo 5 de la ley que la rige le ha permitido desempeñar funciones respecto de la tutela de los consumidores a través del control de las prácticas engañosas o injustas.

Es respecto de las prácticas engañosas que aparecen los desarrollos más interesantes sobre el requisito de transparencia. Entre estos casos existen algunos que corresponden a omisión, en los cuales simplemente no se informa ciertos tipos de interferencia a la privacidad de los usuarios o bien se les informa inadecuadamente, como en el citado Sears (Solove y Hartzog, 2014: 630-636). Estos últimos son los que interesan aquí.

16. La norma ha sido criticada, ya que al contrario del artículo 2, 9:402 del DCFR no estipula una sanción específica para el caso de que el comerciante no cumpla con el deber de transparencia (Mazeaud y Sauphanor-Brouillaud, 2012: 382). 
Según el «FTC policy statement on deception», ${ }^{17}$ para que se considere como engañosa una práctica, ha de ser el caso que se satisfagan los siguientes requisitos: i) una representación, omisión o práctica que confunda (mislead) o resulte apta para confundir; ii) un consumidor actuando razonablemente según las circunstancias, y iii) que la representación, omisión o práctica sea determinante (material) para el consumidor.

De esta manera en Sears, la FTC parece haber considerado ${ }^{18}$ que el correo electrónico que enviaba Sears a los consumidores invitándolos a unirse a su comunidad e informando inadecuadamente acerca del alcance del programa de rastreo constituía una representación u omisión apta para confundir a los consumidores. ${ }^{19}$ En segundo lugar, respecto del comportamiento razonable del consumidor, Fang sugiere que el primer correo electrónico enviado por Sears permitía al consumidor estimar de forma razonable que el alcance del programa de rastreo era extremadamente inferior al que en verdad tenía y que luego se le informaba en el contrato de licencia (Fang, 2010: 693). Por lo que toca al tercer requisito - que la omisión o representación haya sido determinante- la FTC estimó que, atendido el enorme alcance del programa de rastreo, resultaba perfectamente plausible suponer que si el consumidor lo hubiera sabido, simplemente no hubiese ingresado a la comunidad que le ofrecía Sears.

En la decisión del caso Sears, la FTC estimó que, al tratarse del tipo de programa que involucraba dicho caso, Sears debía revelar: ${ }^{20}$ i) antes del contrato de licencia; ii) en una pantalla separada de la del contrato de licencia, y iii) de manera clara y prominente: a) toda la información que el programa rastreaba, b) los usos que se le dará a esa información, y c) si la información va a ser utilizada por terceros.

Se decidió, además, que para la instalación del programa se debía obtener el consentimiento expreso del consumidor y que éste debía manifestarse a través de una acción cuyo significado fuera evidente, como un clic en un botón que indicase claramente que ésa era su función.

Por otra parte, respecto de qué debe entenderse por «clara y prominentemente» (clearly and prominently) se señaló:

a) En comunicaciones textuales (por ejemplo, publicaciones impresas o palabras desplegadas en la pantalla de un computador), la información necesaria será de un

17. «FTC policy statement on deception», Federal Trade Commision de Estados Unidos, 14 de octubre de 1983, disponible en http://bit.ly/2KYZdMK.

18. Seguimos aquí el análisis de Fang (2010: 691-695).

19. El proceso funcionaba de la siguiente manera: una vez que el usuario ingresaba a la página de Sears, se desplegaba una ventana emergente que lo invitaba a formar parte de una comunidad. Si el usuario introducía su dirección de correo electrónico, le llegaba entonces el correo electrónico al que nos estamos refiriendo.

20. Seguimos en esto a Gindin (2009: 18-19). 
tipo, tamaño y ubicación suficientemente notorio para que un consumidor ordinario los pueda leer y comprender, en un color que contraste con el fondo en el cual aparecen.

b) En comunicaciones divulgadas oralmente o por medios de audio (por ejemplo, radio o audio streaming), la información necesaria será entregada en un volumen y velocidad suficiente para que un consumidor ordinario pueda oírlas y comprenderlas.

c) En comunicaciones divulgadas por medios de video (por ejemplo, televisión o video streaming), la información necesaria será entregada por escrito en una forma consistente con el subparágrafo a) de esta definición, y deberá aparecer en la pantalla por una duración suficiente para que un consumidor ordinario los lea y comprenda, y en el mismo lenguaje que el predominante usado en la comunicación.

d) En comunicaciones efectuadas por medios interactivos, como internet, servicios online, y software, la información necesaria será inexcusable y presentada en una forma consistente con el subparágrafo (a) de esta definición, en adición a cualquier audio o presentación de video de ellos; y

e) En todos los casos, la información necesaria sera presentada en un lenguaje y sintaxis comprensible, y sin nada inconsistente o contrario a, o en deterimento de la información usada en dicha comunicación. ${ }^{21}$

De esta manera, el suministro de información debe satisfacer dos requisitos. El primero es que la fuente de la letra, su tamaño y color la hagan suficientemente evidente para un consumidor razonable. El segundo es que el mensaje sea comprensible tanto en lenguaje como en sintaxis, y que en su contenido no haya nada contrario, inconsistente o que debilite otra información que se haya dirigido al consumidor.

Esta decisión, aunque ya junta algunos años, parece reflejar la actual opinión de la FTC respecto de la cuestión.

\section{Dos dimensiones del requisito de transparencia}

Una mirada al desarrollo tanto a nivel europeo como en el ámbito estadounidense sobre el requisito de la transparencia parece mostrar que se desenvuelve en dos dimensiones: la primera se refiere al acceso a la información y la segunda a su comprensibilidad.

Con respecto a la comprensibilidad, podemos recordar la exigencia de la Directiva 93/13/CEE, según la cual las cláusulas de un contrato por adhesión deben estar «redactadas siempre de forma clara y comprensible». O como lo establece el Reglamento 2016/79 del Parlamento Europeo y del Consejo sobre protección de las personas físicas en lo que respecta al tratamiento de datos personales, que es el tema de este

21. «FTC Sears Holding Managment Corporation Decision and Order», Federal Trade Commission de Estados Unidos, 31 de agosto de 2009, página 3, disponible en https://bit.ly/2zHbmSj. 
trabajo: «El principio de transparencia exige que toda información y comunicación relativa al tratamiento de dichos datos sea fácilmente accesible y fácil de entender, y que se utilice un lenguaje sencillo y claro», a lo que el considerando quincuagésimo octavo agrega: «El principio de transparencia exige que toda información dirigida al público o al interesado sea concisa, fácilmente accesible y fácil de entender, y que se utilice un lenguaje claro y sencillo, y, además, en su caso, se visualice».

El mismo Reglamento nos alerta acerca de la segunda dimensión de la transparencia. Como se recordará, su artículo 7.2 exige que la solicitud de autorización del tratamiento de los datos personales «se distinga claramente de los demás asuntos, de forma inteligible y de fácil acceso». Por su parte, el artículo 12.1, bajo el título «Transparencia de la información, comunicación y modalidades de ejercicio de los derechos del interesado», vuelve a referirse al «fácil acceso».

De manera mucho más detallada, como acaba de verse en su decisión en el caso Sears, la FTC detalla cómo ha de ser el acceso cuando se trata de las políticas de privacidad, al señalar que deben presentarse por separado, no al interior del contrato, identificar los requisitos del texto e indicar que el consentimiento debe ser expreso.

\section{El requisito de transparencia en el ordenamiento jurídico chileno}

La problemática que hemos planteado ha sido escasamente examinada en Chile. Al respecto, los autores que han estudiado las cuestiones que suscitan los contratos de adhesión han tratado de manera tangencial el tema a propósito del control de forma o inclusión y, en particular, en relación con los requisitos impuestos por el artículo 17 de la Ley de Protección del Consumidor. Así por ejemplo, Tapia y Valdivia (2002: 72) se refieren al requisito de «claridad», entendido como inteligibilidad, y Pizarro y Pérez (2013: 360-362) mencionan las «reglas de claridad y transparencia», sin desarrollar los aspectos del requisito de transparencia que hemos analizado en este trabajo. Asimismo, Baraona (2014: 381-408) examina lo que denomina «principio de transparencia del proveedor», que relaciona con los deberes de información que distintas normas de la Ley de Protección del Consumidor imponen a los proveedores. Por último, Barrientos Camus (2018) efectúa un examen más acabado, pero aún centrado en el análisis de los requisitos estrictamente formales del mencionado artículo 17.

Por otra parte, una mirada a algunas sentencias de tribunales superiores de justicia en materia de contratos de adhesión muestra que han tomado en cuenta, aunque de manera más bien intuitiva, el requisito de transparencia como una condición de validez de cláusulas incorporadas en dicho tipo de contratos.

Así, sentencias de Cortes de Apelaciones han señalado que, cuando se trata de contratos de adhesión:

Uno de los derechos que se destaca en esta iniciativa legal [la Ley 19.496] es el derecho a la información veraz y oportuna, propendiendo a la transparencia en el 
empleo de la misma, toda vez que ello permite una regulación normal y eficiente del mercado y la adopción de decisiones correctas. ${ }^{22}$

Unido a la libertad de elección está la transparencia, presupuesto básico para la libre elección del consumidor, sobre todo tratándose de contratos de adhesión. ${ }^{23}$

Las reglas de claridad, transparencia e información que deben contenerse en el contrato y en sus condiciones generales deben ser más estrictas. ${ }^{24}$

Estas tres sentencias deciden casos en los cuales una o más cláusulas de los contratos de adhesión impugnados fueron declaradas como abusivas y, por lo tanto, nulas. En todas ellas, el argumento de la falta de transparencia de dichas cláusulas fue utilizado como una más de las justificaciones para la declaración de abuso de las cláusulas.

Si bien el examen de estas sentencias demuestra que el uso del requisito de transparencia parece adecuado al caso concreto, los tribunales, aunque lo intuyen como una condición para la validez de las cláusulas, no lo desarrollan en el sentido que hemos planteado en este trabajo, en sus dimensiones de comprensibilidad y fácil acceso de la información por parte del consumidor.

El escaso tratamiento que ha prodigado la doctrina y los tribunales nacionales al requisito de transparencia nos muestra que, al menos en términos abstractos, no resulta ajeno al ámbito nacional. Sin embargo, en procura de mayor concreción, parece pertinente preguntarse si es posible encontrar un sustento normativo para el establecimiento del requisito de transparencia en la contratación de consumo. Creemos que sí.

El artículo 1 numeral 3 de la Ley 19.496, que define información básica comercial, establece en su inciso cuarto que «la información comercial básica deberá ser suministrada al público por medios que aseguren un acceso claro, expedito y oportuno», norma que se complementa con lo estipulado en el artículo 32, que la información básica comercial deberá «efectuarse en idioma castellano, en términos comprensibles $y$ legibles».

En un sentido similar, el artículo 12.a señala que «en los contratos que se celebren por medios electrónicos, y en aquéllos en que se aceptare una oferta realizada a través de catálogos, avisos o cualquiera otra forma de comunicación a distancia, el consentimiento no se entenderá formado si el consumidor no ha tenido previamente

22. Sentencia de la Corte de Apelaciones de Santiago, rol 1873-2012, 16 de octubre de 2013, considerando tercero.

23. Sentencia de la Corte de Apelaciones de Santiago, rol 8281-2013, 3 de junio de 2014, considerando decimosegundo. Razonamiento reproducido también en la sentencia del 13 de enero de 2015, rol 59922014, considerando undécimo.

24. Sentencia de la Corte de Apelaciones de Concepción, rol 31-2017, 20 de marzo de 2017, considerando segundo. 
un acceso claro, comprensible e inequívoco de las condiciones generales del mismo y la posibilidad de almacenarlos o imprimirlos». El inciso tercero de la misma norma reitera la idea que la copia del contrato deberá ser «íntegra, clara y legible».

Como regla general para todo contrato de adhesión, el artículo 17 indica que «los contratos de adhesión relativos a las actividades regidas por la presente ley deberán estar escritos de modo claramente legible».

En relación con los contratos de adhesión relativos a productos y servicios financieros, el artículo 17.b establece una serie de requisitos que tienen por objeto "promover su simplicidad y transparencia», lo que se refleja, por ejemplo, en las alusiones a la condición de claridad de ciertos términos, que exigen las letras d) y g) de la misma norma.

Por último, debe destacarse que en materia de protección de datos personales, el citado artículo 4 de la Ley 19.628 establece que el titular de los datos «debe ser debidamente informado respecto del propósito del almacenamiento de sus datos y su posible comunicación al público», lo cual puede ser interpretado en el sentido de que la mera información no es suficiente, sino que requiere que ella sea transmitida y puesta en conocimiento del consumidor de un modo especial, que estimamos es justamente mediante el cumplimiento del requisito de transparencia, esto es, con un acceso fácil, y redactada de manera clara e inteligible para un usuario medio.

Pues bien, según creemos, el requisito de transparencia exige accesibilidad y comprensibilidad respecto de la información que el proveedor debe suministrar. Creemos que esa conclusión es perfectamente válida, en el tema que nos interesa al menos, tanto para el ámbito europeo como estadounidense y nacional.

\section{Contratos electrónicos y cláusulas de privacidad}

\section{Contratos browse y clic}

En un trabajo anterior (De la Maza y Momberg, 2017: 25-55) nos hemos detenido sobre si los documentos que contenían políticas de privacidad podían considerarse como contratos. Nuestra conclusión fue que no necesariamente. La razón es que no podía afirmarse en todos los casos que el titular de los datos hubiera aceptado vincularse contractualmente al documento que contenía las políticas de privacidad.

En dicho estudio, según nos parece, demostramos que, en el ámbito de los bienes y servicios prestados por medio de plataformas electrónicas, los «términos y condiciones» con los cuales el proveedor pretende regular su relación con el usuario tienen vocación contractual, es decir, pretenden ser un contrato. La autorización para el tratamiento de los datos personales dependía, entonces, de si el usuario había o no consentido en el contrato que el proveedor le proponía.

Tomando en cuenta la naturaleza de tales documentos -electrónicos y por adhesión- señalamos que, para contestar las preguntas anteriores, era necesario distin- 
guir entre dos caracterizaciones de la forma en que los contratos de adhesión suelen presentarse en plataformas electrónicas: browse y clic. Los primeros se caracterizan porque el proveedor declara que el contrato se entenderá celebrado por el mero uso del servicio o contenido digital, o incluso por la sola visita del usuario a una página web, sin que sea necesario ningún otro tipo de manifestación del consentimiento. En estos contratos, el usuario no requiere dar ninguna manifestación expresa de voluntad para que se entienda obligado por los términos predispuestos por el proveedor, pues basta el mero uso o visita (browse) del sitio o página web. Por su parte, los contratos clic se caracterizan porque requieren del usuario una acción positiva de manifestación de consentimiento para acceder a los servicios ofrecidos por el proveedor a través de la página web. Esta acción consiste habitualmente en pulsar o «hacer clic» en un botón, cuadro de diálogo o casilla que contiene la palabra «Acepto» u otra expresión similar. Lo esencial del contrato clic es que requiere una acción positiva por parte del usuario, la cual es condición para que se complete la transacción. Esta es la diferencia fundamental con los contratos browse, que no requieren manifestación alguna por parte del usuario respecto de los términos que propone el proveedor, los cuales simplemente se encuentran disponibles vía uno o más enlaces, pero sin que el usuario requiera acceder a ellos o realizar alguna acción positiva para completar la transacción y utilizar los servicios.

Siguiendo al derecho comparado, señalamos que la regla general es que se acepte la validez de los contratos clic y, por tanto, el usuario resulte obligado por sus términos. En cambio, la tendencia es que se niegue validez a los contratos browse si el usuario no ha tenido noticia previa suficiente de la existencia de los términos del contrato (Kim 2013; Macdonald, 2011; Trakman, 2009).

Considerando tales distinciones, nuestra conclusión fue que no en todos los casos la aspiración contractual de los «términos y condiciones» se materializa, ya que no en todos los casos resulta posible afirmar que se ha formado un contrato, cuestión que es especialmente cierta respecto de los denominados contratos browse. Como consecuencia de lo anterior, al no haber consentimiento contractual por parte del usuario, tampoco hay autorización para el tratamiento de sus datos personales.

\section{El requisito de transparencia para los contratos clic: Análisis de casos}

Como continuación al trabajo recién mencionado, lo que queremos analizar ahora es si, en el supuesto de que se entienda que se ha formado un contrato - materializado en los «términos y condiciones»- que contenga políticas de privacidad, puede estimarse sin más que la aceptación del contrato legitima el tratamiento de datos personales que autorizan dichas políticas.

En la preparación de ese trabajo, durante el segundo semestre de 2017, se recopilaron y clasificaron las políticas de privacidad de 59 sitios web con presencia en 
Chile. ${ }^{25}$ Se trató de recoger una muestra significativa de políticas de privacidad que incluyese sectores representativos de la actividad económica. Estos sectores fueron retail, servicios bancarios, medios de comunicación, transporte, telecomunicaciones, redes sociales, servicios de streaming y motores de búsqueda.

Los límites de extensión propios de un trabajo como éste no permiten una reproducción íntegra de los términos y condiciones, políticas o cláusulas respectivas de todos los sitios web que hemos examinado, pero entendemos que los extractos que reproduciremos sirven para ilustrar adecuadamente la cuestión. El lector que desee consultar el texto completo de estos instrumentos podrá hacerlo mediante los enlaces de referencia.

La tabla 1 resume el examen de las 59 políticas de privacidad recopiladas, en cuanto a la forma en que se obtenía - o pretendía obtener- el consentimiento del usuario respecto del tratamiento de sus datos personales. Un primer aspecto para resaltar es que los resultados demuestran una clara tendencia de los proveedores a utilizar contratos browse (59,3\%), instrumentos que como hemos señalado, plantean serias dudas respecto de su naturaleza contractual y, por tanto, la legitimidad en el uso y tratamiento de los datos personales de los usuarios.

Pues bien, por razones que ya hemos indicado, no consideraremos aquí la situación de los contratos browse, por lo que nos limitaremos entonces a los clic. Al hacerlo, tendremos presente la distinción entre la dimensión del acceso y de la comprensibilidad del requisito de la transparencia.

\section{La cuestión del acceso}

En nuestra opinión, lo más relevante respecto del acceso a las políticas de privacidad es si se exige que el consumidor o usuario acepte, a través de un clic, únicamente los términos y condiciones de uso del sitio o bien si, además de esto, se requiere por separado su autorización respecto de las políticas de privacidad.

De la tabla 2 puede observarse que existe una tendencia mayoritaria $(70,8 \%)$ a solicitar la autorización específica respecto de las políticas de privacidad del proveedor. No obstante, la tendencia minoritaria — es decir, a no solicitar autorización específica- sigue siendo numéricamente relevante.

Nos interesa mostrar dos ejemplos en los que se infringe - aunque de manera diversa- la dimensión de acceso del requisito de transparencia. El primero de ellos corresponde a Falabella. Para comprar en el portal en línea de la tienda, el usuario debe registrarse. La figura 1 muestra la pantalla en que dicho registro debe efectuarse. ${ }^{26}$

25. Trabajó en esto el ayudante del Departamento de Derecho Privado de la Pontificia Universidad Católica de Valparaíso, Joaquín Calderón Droguett.

26. «Formulario de registro», Falabella, disponible en http://bit.ly/2QdCmmJ. 
Tabla 1. Formas de consentimiento de términos y condiciones en sitios web

\begin{tabular}{|lll|}
\hline Tipo de consentimiento & Cantidad de sitios & Porcentaje \\
\hline Clic general o similar & 24 & $40,7 \%$ \\
Browse & 35 & $59,3 \%$ \\
Fuente: Elaboración propia. & & \\
\hline
\end{tabular}

Tabla 2. Tipos de autorización de política de privacidad solicitada a los usuarios

\begin{tabular}{|lll|}
\hline Tipo de solicitud & Cantidad & Porcentaje \\
\hline Clic general en «Términos y condiciones» 0 similar & 7 & $29,2 \%$ \\
\hline Clic especial en «Políticas de privacidad» o similar & 17 & $70,8 \%$ \\
\hline Fuente: Elaboración propia. & & \\
\hline
\end{tabular}

Como puede observarse, existe un cuadro de diálogo donde el usuario debe, mediante un clic, aceptar los «términos y condiciones». De otra manera, no le es posible adquirir productos en el portal.

$\mathrm{Al}$ acceder a tales términos y condiciones, se despliega un documento que, de acuerdo con su encabezado, contiene los siguientes apartados:

Términos y condiciones del portal de internet www.falabella.cl o www.falabella. com: 1) Aspectos generales; 2) Comunicaciones electrónicas; 3) Tu cuenta; 4) Libertad para navegar y comparar productos y servicios; 5) Cómo comprar o contratar servicios en este sitio; 6) Cambios y devoluciones; 7) Despacho de los productos; 8) Compra online retira en tienda; 9) Retracto legal; 10) Medios de pago que podrás utilizar en este sitio; 11) Políticas de seguridad; 12) Alcance de los precios informados en este sitio; 13) Promociones; 14) Propiedad intelectual; 15) Representante del proveedor; 16) Domicilios; 17) Validez y vigencia de estos términos y condiciones. ${ }^{27}$

Si nos centramos en lo que denominamos el «fácil acceso» a dichas cláusulas, queda de manifiesto que, para un usuario razonable, la presentación de las cláusulas no es suficientemente evidente. En primer lugar, se contienen en un documento de lata extensión y difícil lectura en términos prácticos, ya que requiere un constante deslizamiento vertical en la pantalla del dispositivo para acceder a sus términos. Concretamente, el documento contiene 3.757 palabras, lo que en un documento Word, en hoja tamaño carta, fuente Times New Roman de 12 puntos a espacio sencillo, equivale a ocho páginas.

En segundo lugar, incluso si el consumidor tiene la intención de informarse res-

27. «Términos y condiciones», Falabella, Servicio al cliente, disponible en http://bit.ly/2RyDiyI. 


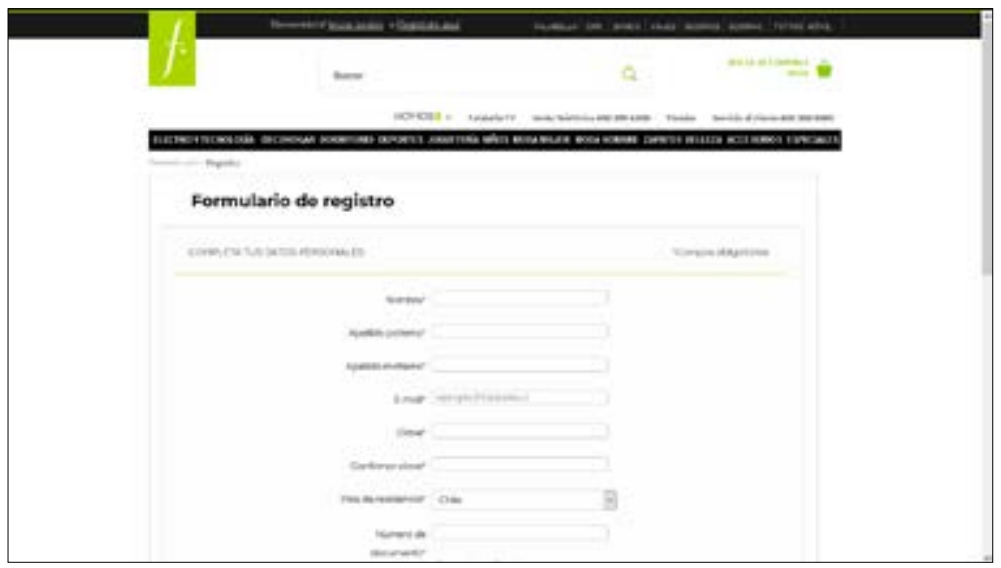

Figura 1. Formulario de registro de Falabella.

pecto del tratamiento de sus datos personales, no hay un apartado que, de manera sencilla y clara, por su denominación, lo conduzca a esa información, la cual se encuentra subsumida en una más general denominada «Politicas de seguridad».

Si se estima que la autorización del consumidor o usuario debe recaer expresamente sobre las políticas de privacidad, entonces debe concluirse que se infringe el requisito de transparencia en lo que refiere al acceso. Tomando lo dispuesto en el artículo 12.a de la Ley de Protección del Consumidor, el consumidor no ha tenido previamente un acceso claro e inequívoco a las condiciones generales del contrato, como tampoco parece ser claramente legible, en los términos del artículo 17 de la misma Ley. En particular, de acuerdo con el artículo 4 de la Ley 19.628, creemos que no ha consentido expresamente en el tratamiento de sus datos personales.

Nuestro segundo ejemplo corresponde a American Airlines. Al ingresar a la página principal de la aerolínea (www.americanairlines.cl), a la fecha de redacción de este artículo, se presentaba la pantalla que muestra la figura 2.

Se trata sin duda de un contrato clic específicamente diseñado para regular la recolección y tratamiento de los datos personales de los usuarios que visitan la página de American Airlines. Esta es la primera cuestión que destacar: tal como lo señala el cuadro de diálogo, se requiere la aceptación de la política para usar el sitio web. Es decir, el usuario queda sujeto a las disposiciones impuestas por el proveedor respecto de sus datos personales, concluya o no una compra de pasajes o de otro producto que se ofrezca en el sitio web. ${ }^{28}$

¿Cómo se presenta dicha política? En un cuadro de diálogo de tamaño evidente-

28. Debe recordarse que este fue uno de los criterios esenciales que la Corte Suprema consideró para declarar abusiva la cláusula sobre datos personales y privacidad de Ticketmaster. Véase considerando undécimo de la sentencia rol 1533-2015 de la Corte Suprema, ya citada. 


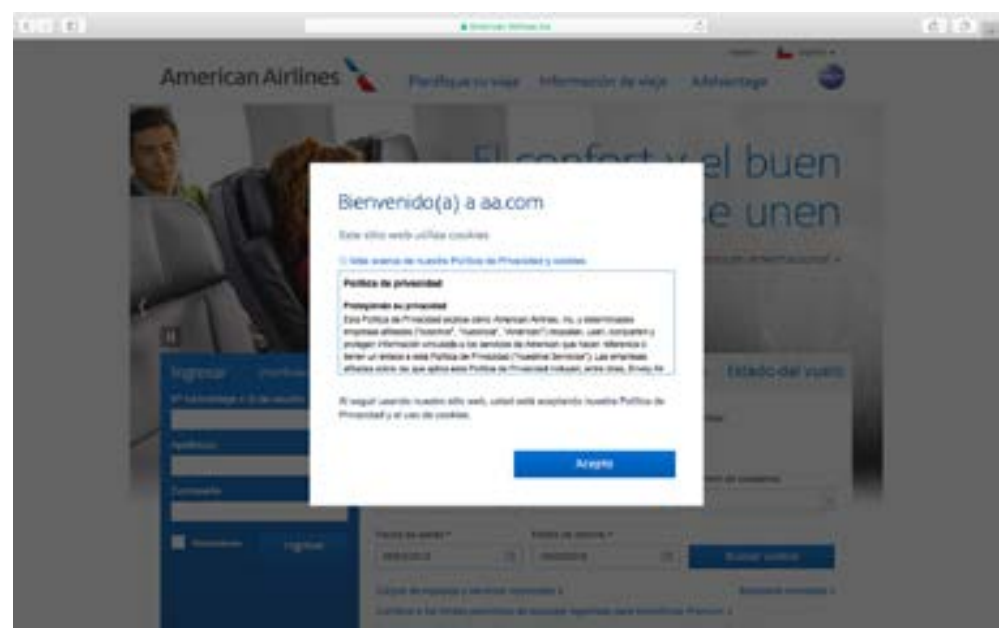

Figura 2. Pantalla principal de American Airlines.

mente menor al de una página web normal, dentro del cual el usuario puede acceder a la política de privacidad que se le propone. Para ello, debe desplazarse verticalmente por dicho cuadro de diálogo (no por la página web) y leer 3.626 palabras en un espacio y tamaño de fuente reducidos.

Hasta aquí, la accesibilidad no parece satisfecha; sin embargo, esto no es todo. Una vez que el usuario ha aceptado la política de privacidad, se tiene acceso a la página web del proveedor. En dicha página web, nuevamente es posible acceder a la política de privacidad. Tras deslizarnos hasta el final de la página principal, entre otros enlaces, se encuentra uno titulado «Políticas e información legal». Al acceder a dicho enlace, se abre una página web titulada «Información legal, privacidad y copyright». ${ }^{29} \mathrm{~A}$ su vez, en la página existe un enlace denominado «Política de privacidad». Por medio de dicho enlace, se tiene acceso a un documento titulado «Política de privacidad», organizado mediante una serie de pestañas desplegables, que efectivamente contiene en su conjunto la política de privacidad del proveedor, la cual, sin embargo, tiene una extensión de $i 4.496$ palabras ${ }^{130}$ Es decir, se trata de dos documentos distintos.

Con estos antecedentes, analicemos la dimensión de accesibilidad del requisito de transparencia. ¿Es una política de privacidad de fácil acceso? Parece evidente que no. La lectura de sus términos en el cuadro de diálogo se hace dificultosa: están escritos en letra pequeña y para leerlos el usuario debe deslizarse constantemente hacia abajo. Lo mismo sucede con la política de privacidad, a la que se accede una vez que se ha

29. «Información legal, privacidad y copyright», American Airlines, disponible en http://bit. $\mathrm{ly} / 2 \mathrm{QiG} 7 \mathrm{Y} 4$.

30. «Privacy policy», American Airlines, disponible en http://bit.ly/2EhoiiK. 
ingresado a la página web del proveedor. Además, como en el caso de Falabella, se trata de un documento extenso, de 3.626 o 4.496 palabras, según el que el usuario pretenda leer.

La conclusión parece ser la misma que para el caso anterior. No es posible entender que se haya cumplido con el requisito de transparencia según lo disponen los artículos 12.a y 17 de la Ley de Protección del Consumidor. En cuanto al artículo 4 de la Ley 19.628, si bien podría entenderse que ha existido consentimiento expreso por parte del usuario, la falta de accesibilidad a la política de privacidad —es decir, su falta de transparencia- determina que la persona que autoriza no haya sido debidamente informada del propósito del almacenamiento de sus datos personales.

\section{La cuestión de la comprensibilidad del contenido}

Por lo que se refiere a la comprensibilidad del contenido de las políticas de privacidad - y considerando los límites de espacio- hemos prestado atención a dos indicadores. El primero de ellos es la generalidad o especificidad de la autorización para el tratamiento de los datos personales. $\mathrm{Al}$ respecto, se pueden diferenciar los casos en que el usuario ha otorgado una autorización de tipo general, definida como aquélla en que no se detallan cuáles datos personales serán recopilados y tratados, sino que se refiere en general a datos generados por el usuario al utilizar el sitio o los servicios del proveedor; y otros en que la autorización es específica, esto es, pormenorizándose los datos personales que serán recopilados. Una tercera categoría incluye a los sitios web en los que no se indica cuáles datos personales se tratarán, sino que solo se hace una indicación aún más imprecisa que en el caso de lo que hemos denominado «autorización general»: por ejemplo, cuando se hace referencia a «la información proporcionada por el usuario» o simplemente no señala cuál es la información o datos a recolectar y tratar.

La tabla 3 muestra esta situación. Los datos destacan claramente que la gran mayoría de las autorizaciones que se presentan al usuario son de carácter general o no indican la naturaleza de los datos que se pretenden recolectar. Esta distinción será importante para analizar la comprensibilidad de estas políticas.

Continuando con el caso de Falabella, analicemos ahora el contenido de las cláusulas sobre privacidad y datos personales que provee la empresa en su sitio web:

Los datos personales que voluntariamente entregues al hacer uso de este sitio, ingresándolos en el link que se ubica en la parte superior de nuestra página web; o bien al completar un proceso de compra, solo podrán ser tratados por Falabella Retail para el llenado automático de los documentos, recibos o comprobantes asociados a tus transacciones y para la operación de los medios de pago disponibles en el sitio; no serán entregados a terceros, salvo cuando la ley lo permita, y solo a empresas relacionadas con Falabella Retail en los términos que define el artículo 100 de la Ley 
Tabla 3. Generalidad o especificidad de la autorización

\begin{tabular}{|lll|}
\hline Tipo de solicitud & Cantidad & Porcentaje \\
\hline General & 15 & $62,5 \%$ \\
\hline Especifica & 1 & $4,2 \%$ \\
No indica & 8 & $33,3 \%$ \\
Fuente: Elaboración propia. & & \\
\hline
\end{tabular}

18.045, con fines exclusivamente comerciales. Falabella tendrá disponible, en este sitio, un listado de esas empresas, que podrás consultar, si lo deseas, haciendo clic sobre el texto «sociedades relacionadas».

Podrás revocar dicha autorización y dispondrás siempre de los derechos de información, rectificación o modificación, cancelación, eliminación y bloqueo de tus datos personales, conforme a la Ley 19.628 sobre Protección de Datos de Carácter Personal. Para ejercer esos derechos, efectuar dicha revocación o modificar la información personal registrada en el sitio, puedes enviar un correo electrónico a servicios@falabella.cl o comunicarte al teléfono 600 380 5000, en horario hábil. También puedes pedirlo en cualquier tienda Falabella. Nuestros ejecutivos atenderán todas estas solicitudes, y podrán solicitar una verificación de la identidad de la persona que se presenta como titular, antes de efectuar los cambios, a través de los medios fehacientes que establece la ley.

El ejemplo ilustra qué entendemos por una autorización general, ya que indica que serán tratados «los datos personales que voluntariamente entregues al hacer uso de este sitio, ingresándolos en el link que se ubica en la parte superior de nuestra página web». No se señala específicamente cuáles son los datos personales por tratar, lo cual es relevante si tomamos en cuenta el carácter extremadamente general con que se definen los datos personales en nuestra legislación..$^{31}$ La falta de comprensibilidad o claridad de la cláusula es manifiesta si comenzamos a cuestionar su sentido: ¿cuál es la página web a que se hace referencia? ¿La página web de inicio? Si el usuario va a «la parte superior» de dicha página web, se encontrará con múltiples enlaces. ¿A cuál de ellos se refiere la cláusula? Y más importante, ¿cuáles son los datos personales que se tratan?

Examinemos ahora, según este criterio, la política de privacidad de American Airlines. Uno de los apartados de dicha política se denomina «La información que recopilamos y cómo la recopilamos»:

Recopilamos y mantenemos la información personal sobre usted desde muchas

31. Artículo 2 letra f) de la Ley 19.628: «Datos de carácter personal o datos personales, los relativos a cualquier información concerniente a personas naturales, identificadas o identificables». 
fuentes para conocer y satisfacer sus necesidades, facilitar su viaje, administrar nuestro negocio y para otros fines que le indicamos. Por ejemplo, recopilamos información personal sobre usted a través de: usted, cuando nos brinda información voluntariamente; sus transacciones con American; otras fuentes de terceros, que le proporcionan servicios y transporte, tales como agentes de viaje, otras aerolíneas (por ejemplo, aerolíneas de código compartido y socias de la alianza) y proveedores de servicios de viaje y alojamiento.

Si la información es recopilada directamente de usted, en algunos casos usted podría tener la opción de negarse a proporcionar dicha información. Sin embargo, su elección de no proporcionar dicha información podría afectar el uso que pueda hacer de determinadas funciones o servicios.

La información personal que recopilamos acerca de usted a través de estas diversas fuentes puede incluir, entre otras: nombre, direcciones y números de teléfono; fecha de nacimiento y género; direcciones de e-mail, números de fax y números de localizadores personales; número de cuenta AAdvantage; número(s) de tarjeta(s) de crédito o débito, incluyendo su(s) respectiva(s) dirección(es) de facturación y fecha(s) de expiración; información necesaria para facilitar viajes u otros servicios, la cual incluye nombres del (los) acompañante(s) de viaje, contactos de emergencia y fotografías; número de pasaporte, nacionalidad y país de residencia; información brindada a través de encuestas, focus groups u otros métodos de investigación de marketing; contrato corporativo, empleador u otra afiliación corporativa (por ejemplo, el nombre del empleador, cargo, dirección del trabajo e información de contacto), incluyendo información de la cuenta Business Extra (por ejemplo, identificación tributaria, tipo de negocio, número de empleados, número de personas que hacen viajes de negocios e información del administrador de los viajes).

En la medida en que la información personal que recopilemos constituya información personal confidencial, según la ley aplicable, American recopilará y procesará esta información personal confidencial dentro de los límites establecidos por la ley aplicable, y únicamente luego de establecer medidas de seguridad razonables para dicha información personal confidencial. En los casos previstos por la ley, American solicitará su consentimiento antes de procesar información personal confidencial.

Si bien a primera vista pudiese pensarse que se trata de una autorización específica, la cláusula es tan amplia que se transforma en una de carácter general. Además, una lectura más atenta demuestra que la enumeración es solo ejemplar, lo que por cierto hace que cualquier intento de especificidad sea simplemente ilusorio. La cláusula además indica que American Airlines puede recopilar información de «otras fuentes de terceros», las cuales solo indica, nuevamente, a modo ejemplar.

La cuestión se complica aún más, ya que, en otro apartado de su política de privacidad, American Airlines informa sobre la «información recopilada automáticamente (incluyendo cookies y geolocalización)». Para no fatigar al lector, transcribiremos solo los dos primeros párrafos de dicho apartado: 
Cuando usted utiliza nuestros servicios, nosotros podríamos recibir información técnica, como por ejemplo el tipo de navegador y de sistema operativo que usted utiliza, su geolocalización, el nombre de su proveedor de servicios de internet, identificadores de publicidad móvil y las páginas visitadas en nuestros servicios. American obtiene esta información mediante el uso de tecnologías, como cookies, web beacons y la geolocalización de los dispositivos móviles, para brindar y mejorar nuestros servicios y publicidad en todos los navegadores y dispositivos (lo que se conoce también como conexión cross-device). También utilizamos esta información para verificar que los visitantes cumplan con los criterios requeridos para procesar sus solicitudes, así como para reportar actividad en nuestros servicios. Por ejemplo, tal vez querramos saber cuánto tiempo pasa un usuario promedio en nuestros servicios o qué páginas u opciones reciben mayor atención. Esta información recopilada automáticamente podría combinarse con información de identificación personal con el fin de personalizar nuestros servicios y publicidad según sus intereses en todos los navegadores y dispositivos.

Asimismo, American puede combinar la información recibida de usted con información recopilada a través de otras fuentes. Esta información podría ser usada para otorgar ofertas y/o servicios que se ajusten específicamente a sus intereses, de conformidad con las leyes aplicables.

La generalidad y vaguedad de las cláusulas transcritas es evidente. Se utilizan frecuentemente descripciones solo a título ejemplar, y se hace referencia, sin especificar, a datos personales que serán proveídos por terceros, que podrían ser combinados - también con propósitos indicados solo a modo referencial- con la información recopilada por American Airlines.

La falta de precisión de las cláusulas, su redacción poco clara y el constante uso de enumeraciones o descripciones meramente ilustrativas, hace que ellas no cumplan con la dimensión de comprensibilidad que exige el requisito de transparencia. Nuevamente, estas cláusulas podrían ser impugnadas en base a lo establecido en los artículos 12.a y 17 de la Ley de Protección del Consumidor, y 4 de la Ley 19.628.

El segundo indicador que consideramos respecto de la comprensibilidad es la descripción del propósito del tratamiento de datos, requisito expresamente contemplado en el artículo 4 de la Ley 19.628. Utilizaremos como ejemplos, nuevamente, las cláusulas o política de Falabella y American Airlines.

Al examinar los términos y condiciones de Falabella, encontramos que el propósito del almacenamiento se informa con detalle:

Solo podrán ser tratados por Falabella Retail para el llenado automático de los documentos, recibos o comprobantes asociados a tus transacciones y para la operación de los medios de pago disponibles en el sitio.

Sin embargo, agrega después que 
no serán entregados a terceros, salvo cuando la ley lo permita, y solo a empresas relacionadas con Falabella Retail en los términos que define el artículo 100 de la Ley 18.045, con fines exclusivamente comerciales.

La vaguedad de esta segunda frase anula completamente la precisión de la primera, lo que puede fácilmente inducir a error al consumidor, pues se ha vuelto incomprensible. ¿A qué se refiere con "fines exclusivamente comerciales»? ¿Quiénes son esos terceros? La referencia a un cuerpo legal no satisface la sencillez y legibilidad que debiese tener la cláusula para un consumidor medio.

Si analizamos ahora la política de privacidad de American Airlines, la situación es similar, ya que dispone en el apartado sobre «Cómo será usada su información» que «nosotros utilizamos información personal para llevar a cabo transacciones y atender el pedido de nuestros productos y servicios», y agrega más adelante que

Además de utilizarla para procesar, confirmar y cumplir con el viaje o algún otro servicio o producto que usted solicite, American puede utilizar información personal para fines administrativos, analíticos y de marketing, tales como para la administración de sistemas de información, contabilidad, facturación y auditorías, procesamiento y verificación de tarjetas de crédito, correspondencia de relaciones con el cliente y/o para el funcionamiento de los programas AAdvantage y Business Extra. American también utiliza información personal para identificar, desarrollar y comercializar productos y servicios que consideramos serán valiosos para usted, incluidos todos los navegadores y dispositivos, de conformidad con las leyes aplicables.

A lo anterior, en otro apartado, titulado «Con quién será compartida su información», se agregan otros propósitos de la recolección y tratamiento de datos:

American no comparte información personal con terceros, excepto de conformidad con la presente política de privacidad. Podríamos divulgar información a empresas afiliadas a American y/o a terceros no afiliados, i) para brindar los productos y servicios solicitados por usted; y ii) para fines administrativos, de análisis y marketing. Por ejemplo, podríamos brindar a terceros información que recopilamos sobre usted, para distribuir promociones, sorteos, encuestas de marketing, focus groups, entrevistas y otras oportunidades que ofrece American.

Igualmente, podemos brindar información personal a terceros, como por ejemplo a los empleadores que hayan coordinado descuentos o comprado viajes u otros servicios en su nombre.

Además, ocasionalmente, nosotros podríamos compartir información con empresas afiliadas a American, tales como Envoy Air Inc., y con determinadas empresas externas con quienes tengamos una relación comercial, lo que incluye a los participantes AAdvantage y Business Extra. Estas empresas podrían enviarle ofertas en función de la información que usted nos haya brindado a nosotros. 
Las dudas acerca de la comprensibilidad, en cuanto claridad y sencillez del lenguaje utilizado en estas cláusulas, son evidentes. Se señalan reglas con un sinnúmero de excepciones, y conceptos abiertos de difícil o imposible determinación. Solo a modo ejemplar: «Podríamos divulgar información a empresas afiliadas a American y/o a terceros no afiliados» (es decir, a cualquiera); «ocasionalmente»; o «determinadas empresas externas con quienes tengamos una relación comercial».

No parece que se cumpla con el requisito de que la cláusula sea comprensible para un usuario medio, y en particular, no parece que se satisfaga la condición establecida en el artículo 4 de la Ley 19.628, que requiere que «la persona que autoriza debe ser debidamente informada respecto del propósito del almacenamiento de sus datos personales».

\section{Conclusiones}

Este trabajo - según confiamos- contribuye a responder una pregunta que puede formularse con sencillez: ¿bajo qué condiciones es legítimo el tratamiento de datos que las políticas de privacidad de sitios web pretenden autorizar? En un trabajo anterior (De la Maza y Momberg, 2017) hemos sostenido que el primer requisito es que se pueda considerar como contrato al documento que contiene las políticas de privacidad. En éste, añadimos que la información que contienen las políticas de privacidad debe ser transparente (en un tercer trabajo, deberíamos ocuparnos de que dichas políticas no deben ser abusivas en términos sustantivos).

Nuestra primera conclusión al abrigo del derecho europeo y estadounidense es que el requisito de transparencia se encuentra ampliamente asentado a propósito de la tutela de los consumidores frente a los contratos de adhesión.

Nuestra segunda conclusión es que, muy plausiblemente, se trata, como lo muestra el caso de la FTC, de un requisito llamado a cumplir una función relevante respecto del tratamiento de datos personales.

En tercer lugar, creemos que se trata de un requisito reconocido - aunque no particularmente desarrollado- tanto por la doctrina como por los tribunales nacionales, pero que, a la luz de las normas disponibles, permite aplicarlo ya sea en su dimensión de accesibilidad como de comprensibilidad.

En fin, en cuarto lugar, una mirada - aun cuando resulte muy leve metodológicamente- a algunos contratos electrónicos en Chile nos permite, de una parte, ilustrar incumplimientos - algunos más flagrantes y otros más sutiles- al requisito de la transparencia. De otra parte, nos permite sospechar que si se examinan exhaustivamente las políticas de privacidad de los sitios que hemos considerado, las conclusiones no serían muy diversas de aquéllas a las que llegamos a través de los dos ejemplos empleados en este trabajo. 
Deseamos terminar advirtiendo que este trabajo forma parte de un proyecto mayor, y eso - además de la extensión que admiten las revistas en Chile- explica, al menos, parte de sus limitaciones. Así, por ejemplo, que no se considere el carácter abusivo o no de las políticas en términos sustantivos, que no se considere con mayor atención los requisitos de aceptación de la Ley 19.628 y la interacción de esa ley con la Ley 19.496 respecto de la especialidad. Con algo de fortuna, esos temas deberían ocupar dos trabajos siguientes.

\section{Reconocimiento}

Este trabajo presenta resultados del proyecto Fondecyt regular 1170983, titulado: «Las cláusulas para el uso y tratamiento de datos personales en la contratación por medios electrónicos: Un análisis desde el derecho de contratos», cuyo investigador responsable es Rodrigo Momberg Uribe, y su coinvestigador es Î́nigo de la Maza Gazmuri.

\section{Referencias}

BARAONA, Jorge (2014). «La regulación contenida en la Ley 19.496 sobre protección de los derechos de los consumidores y las reglas del Código Civil y Comercial sobre contratos: Un marco comparativo». Revista Chilena de Derecho, 41 (2): 381408. DOI: $10.4067 /$ So718-34372014000200002.

Barrientos Camus, Francisca (2018). «Repensando el control de forma de los contratos por adhesión: Una mirada a su aplicación actual y la introducción de la transparencia». En Estudios de derecho civil 13. Santiago: Thomson Reuters.

CaÑIZARES Laso, Ana (2015). «Control de incorporación y transparencia de las condiciones generales de contratación: Las cláusulas suelo». Revista de Derecho Civil, 2 (3): 67-105. Disponible en http://bit.ly/2SyZomi.

De la Maza, Íñigo y Rodrigo Momberg (2017). «Términos y condiciones: Acerca del supuesto carácter contractual de las autorizaciones para el tratamiento de datos personales en sitios web». Revista Chilena de Derecho y Tecnología, 6 (2): 25-55. DOI: 10.5354/0719-2584.2017.46226.

FANG, Yan (2010). «The death of the privacy policy: Effective privacy disclosures after in re Sears». Berkely Technology Law Journal, 25 (1): 671-700. DOI: 10.15779/ $\mathrm{Z}_{3} 8 \mathrm{MH} 50$.

Gindin, Susan (2009). «Nobody reads your privacy policy or online contract? Lessons learned and questions raised by the FTC's action against Sears». Northwestern Journal of Technology and Intellectual Property, 8 (1): 1-37. Disponible en http://bit. ly/2EilLrt.

KIM, Nancy (2013). Wrap contracts: Foundations and ramifications. Oxford: Oxford University Press.

Loos, Marco (2015). «Transparency of standard terms under the unfair contract 
terms directive and the proposal for a common European Sales Law'». European Review of Private Law, 23 (2): 179-193. Disponible en http://bit.ly/2SwC4DU.

MACDONALD, Elizabeth (2011). «When is a contract formed by the browse-wrap process?». International Journal of Law and Information Technology, 19 (4): 285-305. DOI: 10.1093/ijlit/earoo9.

Mazeaud, Denis y Natacha Sauphanor-Brouillaud (2012). «Article 82». En Reiner Schulze (editor), Common European Sales Law (CESL): A commentary. Beck: Hart.

Micklitz, Hans (2014). «Unfair terms in consumer contracts». En Norbert Reich, Hans Micklitz, Peter Rott y Klaus Tonner, European Consumer Law. 2. ${ }^{\AA}$ ed. Cambridge: Intersentia.

Momberg, Rodrigo (2013). «Comentario al artículo 1 número 1: Definición consumidores o usuarios». En Înigo de la Maza y Carlos Pizarro (directores), La protección de los derechos de los consumidores. Santiago: Thomson Reuters.

Morales Moreno, Antonio Manuel (2014). «El control de abusividad de las cláusulas de vencimiento anticipado del crédito hipotecario por falta de pago». En Luis Díez-Picazo (coordinador), Estudios jurídicos en homenaje al profesor José María Miquel. Volumen 2. Navarra: Aranzadi.

Pertiñez Vílchez, Francisco (2013). «Falta de transparencia y carácter abusivo de la cláusula suelo en los contratos de préstamo hipotecario». Indret, 3: 1-28. Disponible en https://bit.ly/2BUg28X.

Pizarro, Carlos e Ignacio Pérez (2013). «Comentario al artículo 17». En Íñigo de la Maza y Carlos Pizarro (directores), La protección de los derechos de los consumidores. Santiago: Thomson Reuters.

Solove, Daniel y Woodrow Hartzog (2014). «The FTC and the new Common Law of Privacy». Columbia Law Review, 114 (3): 583-676. Disponible en http://bit. ly/2Sw2ohx.

TAPIA, Mauricio y José Miguel VAldivia (2002). Contrato por adhesión: Ley 19.496. Santiago: Jurídica de Chile.

Trakman, Leon (2009). «The boundaries of Contract Law in cyberspace». Public Contract Law Journal, 38 (1): 187-236.

\section{Sobre los autores}

IÑIgo de la MaZa Gazmuri es abogado. Doctor en Derecho, profesor de Derecho Civil e investigador en la Facultad de Derecho de la Universidad Diego Portales, Chile.Su correo electrónico es inigo.delamaza@udp.cl.

Rodrigo Momberg Uribe es abogado. PhD de la Universidad de Utrecht. Profesor de Derecho Civil de la Pontificia Universidad Católica de Valparaíso, Chile. Su correo electrónico es rodrigo.momberg@pucv.cl. 


\title{
REVISTA CHILENA DE DERECHO Y TECNOLOGÍA
}

La Revista de Chilena de Derecho y Tecnología es una publicación académica semestral del Centro de Estudios en Derecho Informático de la Facultad de Derecho de la Universidad de Chile, que tiene por objeto difundir en la comunidad jurídica los elementos necesarios para analizar y comprender los alcances y efectos que el desarrollo tecnológico y cultural han producido en la sociedad, especialmente su impacto en la ciencia jurídica.

\author{
EDITOR GENERAL \\ Daniel Álvarez Valenzuela \\ (dalvarez@derecho.uchile.cl) \\ SITIO WEB \\ rchdt.uchile.cl \\ CORREO ELECTRÓNICO \\ rchdt@derecho.uchile.cl \\ LICENCIA DE ESTE ARTÍ́CULO \\ Creative Commons Atribución Compartir Igual 4.0 Internacional
}

\begin{abstract}
y
La edición de textos, el diseño editorial

y la conversión a formatos electrónicos de este artículo

estuvieron a cargo de Tipográfica

(www.tipografica.cl).
\end{abstract}

